\title{
O QUE É PERFORMANCE? ENTRE A TEATRALIDADE E A PERFORMATIVIDADE DE SAMUEL BECKETT
}

\author{
Fernando de Toro ${ }^{1}$
}

Resumo

$\mathrm{O}$ artigo discute as noções de performance, performatividade $\mathrm{e}$ teatralidade, à luz dos conceitos de Goffman e Kaprow, examinando como foram fundamentais para a eclosão do teatro pós-moderno.

Palavras-chave: performance, performatividade, teatralidade.

\begin{abstract}
This article discuss performance, performativity and theatricaly concepts refered to Goffman and Kaprow senses, affirming their axial functions to eruption of post modern theatre.
\end{abstract}

Keywords: performance, performatity, theatricaly.

\section{A noção de performance: um pouco de história.}

A noção de performance foi introduzida por Ervin Goffman em 1959 em seu livro The Presentation of Self in Everyday Life (A Representação do Eu na Vida Cotidiana), sendo a noção de performance art introduzida por Allan Kaprow em 1957, em seu livro Essays on the Blurring of Art and Life (Ensaios nas Sombras entre Arte e Vida, 1993), desde sua primeira performance, 18 Happenings in 6 Parts, realizada em 1959 (KIRBY, 1965). Tais noções vão abrir um novo campo de estudos e uma variedade de disciplinas, incluindo o teatro e diversas formas de espetáculos. Hoje nos encontramos curiosamente frente a uma torre de Babel onde tudo é "performance", a tal ponto que as noções originais de Goffman e Kaprow perderam todo seu valor epistemológico e heurístico, tornando a noção bastante problemática. Esta espécie de significante flutuante que é a noção de performance criou confusões e malentendidos conceituais, visto que, em geral, o rigor científico está ausente no uso de diversos conceitos, entre os quais, além daquele de performance, estão

${ }^{1}$ Professor e pesquisador do Departamento de Inglês, Cinema e Teatro da University of Manitoba, Canadá.

A tradução foi coordenada por Edélcio Mostaço. 


\section{Urdimento}

os de performatividade, paradigma, desconstrução e teatralidade, etc. É necessário, portanto, explicitar a que performance estou me referindo. Também me parece fundamental situar, no tempo e no espaço, a noção de performance e a noção de Performance Studies.

Meu interesse reside, num primeiro momento, numa reflexão crítica sobre a noção de performance; sobre a performatividade e a teatralidade, sobre os anos cinquenta, a que chamei de o fim da modernidade (de TORO, 2010a) e uma reflexão sobre performance e teatralidade pós-modernas. E, num segundo momento, sobre a teatralidade e a performance no teatro de Samuel Beckett.

\section{Performance, performatividade e teatralidade, o fim da modernidade}

1 - Performance

Estas reflexões situam-se num nível epistemológico, e foram introduzidas por Goffman no campo da vida social e por Kaprow (e não por Richard Schchener, como frequentemente se pensa) em relação aos happenings. Para Goffman,

Uma 'performance' pode ser definida como toda atividade de um dado participante numa dada ocasião que sirva para influenciar, sob qualquer modo, qualquer outro participante (1959:15).

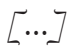

Tenho usado o termo performance para referir toda atividade de um indivíduo que ocorre durante um período marcado pela sua contínua presença frente a um grupo particular de observadores e que tem alguma influência sobre os mesmos (1959, p. 22).

$\mathrm{O}$ aspecto fundamental aqui é a presença de um indivíduo frente a um público e, nesta acepção, a definição de Goffman aproxima-se daquela de Grotowski:

Mas o teatro pode existir sem atores? Eu não conheço nenhum exemplo. $O$ teatro pode existir sem público? Pelo menos um espectador é necessário para se fazer um espetáculo. Assim, nos resta o 


\section{Urdimento}

ator e o espectador. Nós podemos então definir o teatro como 'aquilo que ocorre entre um espectador e um ator'. Todas as outras coisas são suplementares - podem ser necessárias, mas ainda assim suplementares (1971, p. 30-31).

Quer para Goffman quer para Grotowski, o aspecto fundamental é a presença de um indivíduo frente a um público. Este indivíduo recorre à uma máscara para assumir seu papel, o que Goffman chama de fachada (front) e que em português ${ }^{2}$ pode ser entendido como um duplo rosto ou o duplo.

A interação (isto é, a interação face a face) pode ser definida, em linhas gerais, como a influência recíproca dos indivíduos sobre as ações uns dos outros, quando em presença fisica imediata (1959: 22). [...] interação pode ser definida como toda interação que ocorre em qualquer ocasião, quando, num conjunto de indivíduos, uns se encontram na presença imediata de outros (1959, p. 22).

Dito de outra forma, o indivíduo realiza uma "execução", uma ação que indica assumir uma persona que não pertence ao sujeito da performação. Esta persona tem como objetivo uma ou várias expressões cujo objetivo é assumir uma identidade qualquer. Assim, como afirma Goffmam,

Além do fato de que diferentes rotinas podem empregar o mesmo cenário, será notado que uma determinada fachada social tende a se tornar institucionalizada em termos de expectativas estereotipadas abstratas que origina, tendendo a assumir um significado e estabilidade além das tarefas específicas que ocorrem no momento para ser executado em seu nome. A interação torna-se uma 'representação coletiva' e um fato em seu próprio estatuto (1959, p. 27).

Isso quer dizer que certas faces se codificam e uma coletividade de performers pode delas se apropriar. Por outro lado, podem, potencialmente, adquirir o estatuto de estereótipos. Goffman estabelece uma relação dialética entre performance social e performance teatral, tomando elementos do teatro para descrever o social e elementos do social para descrever o teatro.

Primeiro, há o 'cenário', compreendendo a mobília, a decoração, a disposição física e outros elementos de pano de fundo que vão constituir o cenário e os suportes do palco para o desenrolar da ação humana executada diante, dentro ou acima dele. $O$ cenário tende a permanecer na mesma posição, geograficamente falando, de modo que aqueles que usem determinado cenário como parte de sua representação não possam começar a atuação até que tenham se colocado no lugar adequado e devem terminar a representação ao deixá-lo (1959, p. 22). 
Urdimento

${ }^{3}$ Neologismo do autor para quem produz assamblages. (NT)

4Seu livro $A$ arte da performance: do futurismo ao presente, é de uma riqueza excepcional no que diz respeito a performance, com detalhadas descrições de espetáculos desde o começo do século XX. Para todos aqueles que estudam a performance, trata-se de leitura obrigatória.

\section{$[\cdots]$}

"Quando um ator assume um papel social estabelecido, geralmente verifica que uma determinada fachada já foi estabelecida para ele" [1959, p.27]

$$
[\cdots]
$$

Desse modo, quando é dada uma nova fachada a uma nova tarefa, raramente verificamos que a fachada dada é, ela própria, nova. $[1959$, p.27].

O que se destaca nestas citações é a teatralidade, em sentido amplo, a performance social marcada pela performance teatral. Este aspecto da performance social que se torna teatro nos lembra a noção de apropriação de discursos (que inclui gestos, comportamentos, tons de voz, etc) de Barthes (A morte do autor, 1984), de Foucault (O que é um autor?, 1994) e, sem dúvida, de Bakhtin e sua noção de heteroglossia (A imaginação dialógica, 1981). A incorporação da palavra do Outro, inclui na literatura, no espetáculo vivo, como também na vida social não somente a palavra, mas também o gesto. Com The Presentation of Self in Everyday Life, os estudos sobre a performance nasceram no campo social e foram expandidos em outro livro seminal de Goffman, Frame Analysis: An Essay on the Organisation of Experience (1974) e por toda uma série de outros livros por ele escritos, principalmente entre os anos 1960 e 1970.

Goffman terá também um impacto sobre o pensamento de Kaprow, particularmente no que diz respeito à relação entre espetáculo vivo (performance) e a vida social, que Kaprow irá explorar e construir com os happenings, Fluxus e Activities. Kaprow é quem inicia a Performance Art, sendo ele um assamblagista ${ }^{3}$ e pintor. Ele foi também o criador da Installation Art, que irá se desenvolver entre os anos de 1960 e 1970 e, sem dúvida, praticava este tipo de arte desde os anos 1950. A Performance Art começa objetivamente quando introduz o happening em 1957, como uma forma espetacular que podia incorporar diferentes outras práticas espetaculares que começaram a surgir nesses anos. A noção de happening foi adotada imediatamente em diversos continentes por milhares de artistas. Há um antecedente importante anterior a Kaprow: o Happening e a Theatre Piece n.1 apresentados por John Cage no Black Mountain College, em 1952. Esta obra é também uma primeira performance e contava com a participação do compositor David Tudor (tocando piano preparado), Merce Cunninham (dançando), Robert Rauschenberg (que ouvia um disco arranhado e exibia algumas de suas pinturas), Charles Olson (que lia poemas em cima de uma escada). Podemos, inclusive, remeter-nos ainda mais 
ao passado no que diz respeito aos antecedentes, se seguirmos Goldberg ${ }^{4}$, que investiga a performance como expressão artística desde início do século XX, a partir do Futurismo, do Construtivismo, do Dadá, do Surrealismo, da Bauhaus, etc.

Durante os anos 1950 e 1960, as performances, os happenings tornamse um evento espetacular, especialmente em Manhattan, com artistas como Robert Delford, Jim Dine, Red Grooms, Claes Oldenburg, Carolee Scheemann ou Robert Whitman.

O conceito e a prática da performance art nascem com a Installation Art e a land art. É também o momento da new media art, vídeo, música eletrônica, teatro de rua, a arte conceitual de Sol Lewitt que, no início dos anos de 1960, introduz o estilo muralista como performance, etc. O traço comum em todas essas práticas espetaculares é a especificidade do espaço, sua relação com o público e o hic et nunc, ou seja, o fato de que as performances são de caráter efêmero. Por isso, a noção de performance art, desde seu início, tanto no caso de Goffman quanto de Kaprow, contavam com uma definição bastante precisa, como se pode constatar em seu artigo de 1976, Nontheatrical Performance:

Normalmente, uma performance é uma espécie de jogo, dança, ou concerto apresentado para um público - mesmo na vanguarda. Mas, na verdade, existem dois tipos de performances sendo realizadas atualmente por artistas: uma predominantemente teatral, e outra, menos reconhecida, não-teatral. Elas correspondem, curiosamente, aos dois significados da palavra performance em inglês: um se refere ao desempenho artístico, como na execução do violino; o outro tem a ver com a realização de um serviço ou função, como na realização de uma tarefa, serviço ou dever - viz. um "motor de alto desempenho (1993a, p.173).

\section{$[\cdots]$}

A performance não-teatral não começa com um envelope contendo um ato (a fantasia) e um público (aqueles afetados pela fantasia). No início dos anos sessenta os eventos mais experimentais, tais como happenings e Fluxus tinham eliminado não só os atores, os papéis, enredos, ensaios, e repetições, mas também o público, a própria área do palco, e o período de tempo habitual de aproximadamente uma hora. Estas são práticas de comércio de qualquer teatro, passado ou presente. (1993a, p. 173). 


\section{$[\cdots]$}

Desde estes primeiros experimentos, Atividades, Landworks, Concept pieces (Peças conceituais), Information pieces (Peças de informação) e Bodyworks (Trabalhos corporais) se somaram à ideia de que uma performance não é teatro. Além de meu próprio trabalho e os exemplos de Vostell e Brecht, antes descritos, não é difícil perceber os aspectos de performance numa conversa telefônica, ao se cavar uma vala no deserto, distribuindo folhetos religiosos em uma esquina, recolhendo e organizando as estatísticas demográficas ou tratando o corpo de alguém alternando imersões em água quente e fria (1993a, p. 174).

Citei esses textos para demonstrar que a noção de performance que vai se tornar um gênero nos anos 1970 é claramente introduzida por Kaprow, distinguindo-se por uma diferença fundamental: a performance dos happenings é coletiva, enquanto a performance dos anos 1970 em diante, é individual.

Em seu artigo Performance and Theatricality: The Subject Demytified (Performance e Teatralidade: O Sujeito Desmistificado, 1982), Josette Fèral define três características que são fundadoras da performance: o corpo do performer, o trabalho que o performer realiza com seu corpo e a construção de um espaço. O performer constrói um espaço: aqui reside a performance, e a performação somente pode ser realizada no e para o espaço construído que está indissoluvelmente ligado ao performer: neste espaço o sentido desaparece (FÉRAL, 1982, p. 171-173). Féral acrescenta que a performance não é uma forma pré-estabelecida, "pois cada performance constitui sua própria forma, seu próprio gênero”(FÉRAL, 1982, p. 174). Por fim, ela sustenta que na performance, geralmente, não há relato porque a performance não relata nada e não imita ninguém; a performance se separa da ilusão e da representação: disso deduz-se que a performance parece um processo no qual a teologia está ausente, uma vez que a performance não representa nada para ninguém. Assim, também a teatralidade encontra-se ausente na performance (FÉRAL, 1982, p. 177-179). Alguns aspectos desta definição podem ser aplicados também à performance do happening, tais como a ausência de mímesis, de teatralidade e de forma.

A partir dos textos que acabamos de citar, podemos estabelecer uma relação muito clara entre Kaprow e Goffman: o vínculo entre a performance e a vida, onde a performance está fora do teatro mas, sem dúvida, constitui um espetáculo. A própria definição de "performance não-teatral" aproxima-se daquela de Goffman. Em um artigo de 1977, intitulado Participation Performance, Kaprow estabelece tal relação: 
No final dos anos 1950 Ervin Goffman publicou The Presentation of Self in Everyday Life, um estudo sociológico sobre as relações humanas convencionais. Sua promessa foi de que as rotinas da vida doméstica, trabalho, educação e gestão de assuntos diários que, devido à sua grande simplicidade e falta de propósito expressivo consciente não parecem ser formas de arte possuem, no entanto, um caráter nitidamente semelhante à performance. (1993a, p. 186).

\section{$[\cdots]$}

O que é interessante para a arte, porém, é que as rotinas diárias poderiam ser utilizadas realmente como performances fora do palco. Um artista estaria, assim, envolvido em desempenhar uma 'performance'. (1993a, p. 187).

É precisamente a partir daqui que Kaprow trabalha a prática do Happening e da vida cotidiana, p.

Viver a vida, conscientemente, era uma noção atraente para $\operatorname{mim}(1993$ b, p. 195).

\section{$[\cdots]$}

Quando você vive conscientemente, porém, a vida se torna muito estranha - prestar atenção muda a coisa que se faz - então os happenings não eram tão reais como eu havia imaginado que poderiam ser. Mas eu aprendi algo sobre a vida e "vida"(1993b, p. 195).

\section{$[\cdots]$}

Um novo gênero de arte/vida surgiu, refletindo igualmente os aspectos artificiais da vida cotidiana e as qualidades reais de arte criada (1993b, p. 195).

Assim, quanto mais a arte do espetáculo se aproxima da vida, mais se assemelha ao happening.

Kaprow não apenas introduz e define a performance, como também os Performance Studies (Estudos da Performance) com o mesmo significado e extensão que Richard Schechner fará vinte anos mais tarde, em Essays on Performance Theory (Ensaios sobre Teoria da Performance, de 1977). Ao estabelecer a diferença entre "performance teatralizada" e "performance não- 


\section{Urdimento}

teatralizada” (1993, p. 163-80), Kaprow introduz uma forma de não-arte que se torna uma nova arte e, para ele, "um artista escolhendo fazer performances não-artísticas simplesmente tem que saber o que são performances teatrais e evitar fazê-las, de maneira consciente, pelo menos no início"(KAPROW, 1993a, p. 175).

No mesmo artigo, Kaprow introduz uma série bastante complexa de campos de estudos da performance, estudos que, ao final dos anos 1970, tornarse-ão extensivos:

Quando você tenta interagir com a vida animal e vegetal, com o vento e as pedras, você até pode ser um naturalista ou engenheiro de estrada, mas você e os elementos são performers - e esta pode ser a busca básica (1993a, p. 177).

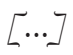

Quando você usa o sistema postal para enviar cartas ao redor do mundo para pessoas conhecidas ou desconhecidas, e quando você, em modo similar, usa o telefone, o telégrafo ou o jornal - estes transportadores de mensagens são performers e esta comunicação pode ser a busca básica (1993a, p. 177-178).

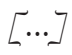

Quando você experimenta com as ondas cerebrais e processos relacionados com bio-respostas a fim de se comunicar consigo mesmo, com os outros e com os mundos não-humanos, estas podem ser a busca básica (1993a, p. 178).

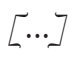

Quando você olha para uma rotina normal em sua vida como uma performance e cuidadosamente projeta por um mês como você cumprimenta alguém a cada dia, o que você diz com seu corpo, suas pausas e sua roupa, e quando você projeta cuidadosamente as respostas que você recebe, esta pode ser a busca básica (1993a: 178-179).

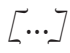

Quando vocêfica atento em como sua performance afeta sua vida real e a vida real de seus co-performers e quando você presta 
atenção em como ela pode ter alterado o ambiente social e natural - isto pode ser a busca básica (1993a, p. 179).

\section{$[\cdots]$}

Quando você colabora com um trabalho acadêmico sóciopolítico e educacional; e quando você dirige sua performance para alguma utilidade definida - isto pode ser a busca básica. Sendo intencional, isso não é nem arte pronta (ready-made) nem atuar apenas a vida real, uma vez que seu valor é medido pelo seu rendimento prático (1993a, p. 180).

Estes textos estabelecem campos muito diversos e complexos de inter-relações humanas na cultura em geral. É por isso que vejo neles o início mesmo dos campos dos Estudos da Performance como conhecemos hoje. Em Goffman e Kaprow, a noção de performance é clara e não se presta a confusões. Contudo, o que vem a seguir vai transformar essa noção de tal forma que a tornará incompreensível.

\section{Performatividade}

Em diversos estudos teóricos sobre a performance, com freqüência encontramos as noções de performance e performatividade como sinônimas. Por exemplo, Schechner sustenta que:

A performatividade - ou, comumente, 'performance' - está em todo lugar na vida, desde simples gestos até macrodramas. Mas a teatralidade e a narratividade são mais limitadas, ainda que pouco (2009, p. 326).

A performance como gênero pertence a uma época bem precisa, e como atividade espetacular está presente em toda relação que inclui espaço, público e performer. Pois bem, o conceito de performatividade, como sabemos, após mais de um século, provém da filosofia da linguagem, particularmente de Austin e, posteriormente, de Recanati, de Ducrot e também de Searle e muitos outros teóricos. Portanto, é necessário esclarecer de que conceito de performance ou de performatividade estamos falando.

Em relação à performatividade, como um atributo da linguagem, a noção foi assim introduzida (1962): 
[...] proferir uma sentença é, ou é uma parte de, fazer de uma ação, o que também não seria normalmente descrito como tal, ou como “apenas", dizer algo (AUSTIN, 1975, p. 5).

(E. a) "Aceito" (sg. Aceito esta mulher para ser minha legítima esposa) - como empregado numa cerimônia de casamento.

(E. b) "Nomeio este navio o Rainha Elizabeth" - como dito quando é quebrada a garrafa contra o navio.

(E. c) "Eu dou e delego meu relógio para o meu irmão" como ocorre em um testamento.

(E. d) "Aposto seis centavos com você que vai chover amanhã (AUSTIN, 1975, p. 5).

Parece claro, nestes exemplos, que proferir a sentença (nas circunstâncias apropriadas, naturalmente) não é descrever meu fazer sobre aquilo que deveria ser dito, mas oferecer o estar fazendo ou afirmar que farei isto (AUSTIN, 1975, p.6).

\section{$[\cdots]$}

Como chamamos uma frase ou enunciado deste tipo? Proponho chamá-la de uma frase performativa ou um enunciado performativo, ou, em suma, 'um performativo'. O termo 'performativo' é usado em uma variedade de cognatos e construções, tanto quanto o termo 'imperativo' o é. O nome é derivado, evidentemente, de 'performance', o verbo usual com o substantivo 'ação': indicando que a emissão do enunciado é a realização de uma ação - não sendo pensada, normalmente, apenas como dizer algo (AUSTIN, 1975, p. 6-7).

Há, assim, uma reflexividade na noção de performatividade. Em Austin ela é, portanto, reflexiva, na medida em que o ato de falar condiz com o ato de atuar. A performatividade pode, então, ser percebida como um atributo de um tipo preciso de performance: uma performance pode ser performativa, mas o performativo nunca pode ser performance. 
a) Performatividade segundo Austin:

A performatividade reside na coincidência entre o significado e o significante. O problema inscrito nos textos não é constativo, ou seja, não necessita uma descrição explicativa das ações em cena: estas ações são a problemática, por isso são performativas. Por exemplo, a diferença entre o teatro existencialista de Camus ou de Sartre e o de Beckett ou Ionesco reside, precisamente, no fato de que o primeiro é constativo, ou seja, executa uma “discussão" do absurdo da vida, enquanto que no segundo não se discute o absurdo, mas ele é atuado: basta, para ilustrar nosso propósito, evocar Esperando Godot, de Samuel Beckett, obra cuja estrutura é circular, na qual as duas partes do texto começam e terminam da mesma forma e onde os "diálogos" entre Vladimir e Estragon são desprovidos de todo sentido. Assim, nesse caso, a performance do absurdo é performativa.

Segundo Austin, para que exista um ato performativo é necessário que sempre exista uma coincidência entre a palavra e a ação, como no enunciado "eu batizo". Trasladado ao teatro, trata-se, então, de uma palavra que designa uma ação ou de uma ação que performativiza a palavra. Qualquer outro emprego da noção de performatividade é uma extensão metafórica. É por isso que a incorporação desta noção nos Estudos da Performance é uma total alteração da noção original enunciada por Austin.

b) Performatividade segundo d'Aubignac:

Em 1715 François-Héledin, o Abade d’Aubignac na Prática do Teatro afirmou:

É verdade que nos discursos que se fazem, devem eles ser como as ações das quais elas provêm; uma vez que Falar, é Agir (D'AUBIGNAC, p. 1971).

Com efeito, encontra-se aqui uma segunda noção de performatividade : a palavra teatral no espaço cênico torna-se ação na medida em que os acontecimentos não são narrativizados para veicular o relato. Mas porque também a palavra, seja ela extra-diegética ou intra-diegética, fala de acontecimentos da extra-cena ou da intra-cena. A palavra teatral, portanto, é indissociável de sua performatividade em relação ao desenvolvimento dos acontecimentos. Mas não devemos, sem dúvida, deduzir disso que toda performance é performativa; mas, por outro lado, podemos concluir que toda palavra teatral caracteriza-se por ser performativa. 


\section{Urdimento}

\section{Teatralidade}

A noção de teatralidade que aqui empregamos foi introduzida por Roland Barthes em 1954 e 1963, respectivamente, nos Ensaios críticos de 1964. Esta definição não foi jamais superada. No capítulo $O$ teatro de Baudelaire, assinala:

O que é a teatralidade? É o teatro menos o texto, é uma espessura de signos e de sensações que se edifica em cena a partir do argumento escrito, é essa espécie de percepção ecumênica dos artifícios sensuais, gestos, tons, distâncias, substâncias, luzes, que submerge o texto sob a plenitude de sua linguagem exterior (BARTHES, 1964, p. 41-42).

Esta definição por negatividade especifica que o teatro é performance e que a performance teatral comporta a teatralidade ("os artifícios sensuais, gestos, tons, distâncias, substâncias, luzes, que submerge o texto sob a plenitude de sua linguagem exterior"). Ou seja, não há teatro sem teatralidade; é o tex to (o argumento escrito) que se põe em cena ou, num sentido mais amplo, se poderia dizer: a palavra em cena ou a encenação da palavra: eis aqui a especificidade fundamental do teatro. Em Literatura e diferença, no mesmo livro, Barthes desenvolve mais essa noção:

O que é o teatro? Uma espécie de máquina cibernética. Em repouso, esta máquina está escondida atrás de uma cortina. Mas a partir do momento em que a descobrem, ela põe-se a emitir em vossa direção um certo número de mensagens. Estas mensagens têm de particular, o serem simultâneas e contudo de ritmo diferente; em determinado ponto do espetáculo, você recebe ao mesmo tempo seis ou sete informações (vindas do cenário, dos trajes, da iluminação, da localização dos atores, de seus gestos, da sua mímica, da sua fala), mas algumas destas informações mantêm-se (é o caso do cenário), enquanto outras giram (a fala, os gestos; estamos, pois, perante uma verdadeira polifonia informacional, e é isso a teatralidade : uma espessura de signos (falo aqui em relação à monodia literária, e deixando de lado o problema do cinema) (BARTHES, 1964, p. 258).

A teatralidade, concebida como uma espessura de signos, inscreve o teatro como pura teatralidade, e por isso é inconcebível separar o teatro da teatralidade: o teatro não pode ser senão teatralidade. Josette Féral sustenta que "a teatralidade aparece como uma estrutura transcendental" (FERAL, 1988, p. 352), que se encontra também presente na vida cotidiana. Mas, independentemente 


\section{Urdimento}

desse fato, a teatralidade define o teatro, ao menos aquilo que ainda entendemos como teatro: um público, uma atriz, um espaço de jogo, uma dada ficção. A marca da teatralidade teatral consiste na semiotização intencional do acontecimal, e é aqui onde se encontra a "espessura de signos”, essa solicitação da cena pelo olhar do espectador, que atrai toda a atenção do espectador que, por sua vez, encontra-se repleto de signos que a ele se dirigem simultaneamente e em grande número.

Toda representação é um ato semântico extremamente denso: relação do código com a representação (isto é, da língua com a fala), natureza (analógica, simbólica, convencional?) do signo teatral, variações significantes desse signo, restrições de encadeamento, denotação e conotação da mensagem, todos estes problemas fundamentais da semiologia estão presentes no teatro; podemos até mesmo dizer que o teatro constitui um objeto semiológico privilegiado, visto que o seu sistema é aparentemente original (polifồnico) em relação ao da língua (que é linear) (BARTHES, 1964, p. 259).

Citei in extenso a definição de Barthes com a finalidade de mostrar a profundidade e a transcendência desta definição, válida até os dias de hoje.

A noção de performance teatral entende-se, pois, como a localização de uma atriz ou um ator, de uma problemática (ficção-simulação) e de um jogo. A performance teatral pós-moderna, por exemplo, não performatiza uma palavra ou um espetáculo, mas uma problemática. Uma problemática que se torna central não somente para o teatro como para toda a cultura pós-moderna. O que é teatralizado, portanto, é intencionalmente colocado como signo, a relação entre passado e presente. Para compreender como funciona a performance teatral pós-moderna é necessário explicitar alguns conceitos-chave.

\section{O fim da modernidade e os vários pós}

Durante os anos de 1970 as noções de performance e teatro pósdramático tentaram abarcar todas as formas dramáticas que emergiram desde os anos de 1950 e 1960. Dois aspectos merecem ser observados. O primeiro, o que chamei de fim da modernidade (de TORO, 2010 a). Em geral, isso não foi discutido na investigação teatral como o foi na música, arquitetura, literatura, pintura, dança etc., onde, curiosamente, da modernidade às diversas pós-teatralidades, sem pensar o fim da modernidade, e, mais, considerando-se a pós-modernidade como uma extensão degradada da modernidade, e nisso não parece haver contradição. ${ }^{5}$

${ }^{5}$ Alguns teóricos, como Jürgen Habermas, sustentam que a modernidade é um projeto incompleto (1996). 
Os anos de 1950 constituem os anos de fim da modernidade, uma vez que todos os procedimentos estéticos são levados a seu limite, e por isso, conduzindo a uma clausura. É este momento em que se produz o Übervindung que constitui a transição da modernidade para a pós-modernidade: um espaço de transição. É a época de John Cage, de Samuel Beckett, de Karl-Heinz Stockhausen, de Andy Warhol, de Joseph Alberts, de Mark Rothko, de Jackson Pollock, de Luciano Berio, de Merce Cunningham etc.

Nos anos que se seguem, particularmente entre 1960 e 1970, nasce o teatro denominado "coletivo", a partir de grupos. Trata-se, na Europa, nos Estados Unidos e sem dúvida para a América Latina, do período do happening, do teatro-invisível, do Living Theatre, do teatro de Jerzy Grotowski com o Teatr Laboratorium em 1965, de Tadeuz Kantor a partir de 1950 etc. Embora sejam práticas teatrais muito diferentes, elas se caracterizavam pelo abandono do texto dramático, incluindo a palavra (embora Grotowski e Kantor no começo de suas carreiras tenham trabalhado com textos dramáticos). Também temos de mencionar nesse período Eugenio Barba e o Odin Teatret, Arianne Mnouchkine e o Théàtre du Soleil, Augusto Boal e o Teatro de Arena (1956) e o Teatro do Oprimido (1971) etc. Nos Estados Unidos surge um grande número de formas de espetáculos, tais como os happenings de Kaprow, performances de todo tipo, a Performance Art, instalações, teatro de rua, media art etc. Tratase, pois, de uma época de experimentação e de profundas mudanças que anunciavam a morte do texto e, portanto, a morte do autor dramático.

Apesar das diferenças existentes entre estas novas formas de espetáculo, o que as caracteriza é o abandono das formas tradicionais, a busca de novas formas de expressão, o abandono do texto na grande maioria dos casos, a libertação da cena à italiana etc. É por isso, eu penso, que os teóricos do teatro tentaram classificar estas novas formas fortemente heterogêneas sem dar-se conta de que se tratava de um momento de transição, onde os artistas procuravam sair da modernidade teatral e cultural.

Dois exemplos representativos dessa transição são Jerzy Grotowski e Tadeuz Kantor. Seus trabalhos teatrais começam quando a modernidade artística já está concluída. Ainda que suas práticas artísticas tenham sido muito diferentes, seus trabalhos se caracterizam por alguns elementos em comum, a saber: uma busca que apontava a separação do texto ; alterações profundas na concepção do espaço cênico e na encenação em geral ; uma nova abordagem com respeito ao ator ; a encenação como signos e a valorização do espectador. Tais características, por sua vez, vão transitar ao novo teatro coletivo e a todo tipo de espetáculos, tais como os de Augusto Boal, o Living Theatre de Beck e Malina e o happening de Allan Kaprow, que terá ressonância em vários continentes. 


\section{Urdimento}

Acatando este postulado, a saber, que as manifestações artísticas dos anos de 1950 buscavam desfazer-se da modernidade artística, devemos, então, aproximarmo-nos de uma forma radicalmente nova de teatro dos anos de 1960 até o final do século vinte. O teatro que vem depois dessa época de intensa experimentação é parte da pós-modernidade cultural e artística.

\section{Teatralidade e performance pós-modernas}

Eu penso que o aparecimento de todas estas noções que aspiram definir práticas espetaculares que emergem dos anos de 1950 e 1960, tais como o teatro pós-dramático ou o teatro performance se explicam por uma falta de compreensão do que ocorreu nos anos de 1950 com o surgimento do teatro pós-moderno que se seguiu.

Esse mesmo movimento é observado na arquitetura, na música, na pintura, literatura e, sem dúvida, no teatro: a pós-modernidade. Autores como Tom Stoppard, Griselda Gambaro, Botho Strauss, Marco Antonio de la Parra, Edward Bond, Juan Antonio de la Parra, Heiner Müller, Eduardo Pavlovsky, Bernard-Marie Koltès, Arnold Pinter, Valére Novrina, Alejandro Finzi, Peter Hanke, Daniel Veronese, Alberto Kurapel, Nancy Huston etc., são alguns exemplos de textualidade pós-moderna. Por outro lado, o mesmo fenômeno se dá na prática teatral em diretores como Eugenio Barba, Patrice Chéreau, Luis De Tavira, Robert Wilson, Ramón Griffero, Antunes Filho, Gerald Thomas, Alberto Ure, Enrique Buenaventura, Juliana Faesler etc.

A teorização da cultura, literatura, arquitetura, música, pintura pósmodernas desenvolve-se em modo exaustivo, ao menos desde 1979, com a publicação de $A$ condição pós-moderna, de François Lyotard, seguida de estudos seminais como os de Hans Bertens, Madan Sarup, Chris Weedon, Linda Hutcheon, Andreas Huyssen, Charles Jencks, Douwe Fokkema, Ihab Hassan, Paolo Portoghesi, Nigel Wheale, Raymond Williams, para mencionar alguns livros e artigos publicados sobre a pós-modernidade. Parece-me inconcebível que, a pesar de toda essa atividade cultural designada como pós-moderna, o teatro seja a única atividade artística que não seria pós-moderna!, não afetado pela condição pós-moderna, mas por toda espécie de pós-qualquer-coisa como nos informam as estrelas intelectuais da teoria teatral mais recente, que não se fundamentam num rigor epistêmico informado. ${ }^{6}$ Este mesmo problema surgiu com a semiologia teatral quando os "iluminados" de sempre afirmavam que ela não poderia dar conta do espetáculo, inclusive porque sabíamos, graças aos semiólogos de Praga ${ }^{7}$, que este projeto era de fato realizável. Mais tarde, durante os anos de 1970 e 1980, a semiologia teatral se desenvolveu não como um sistema de análise axiológico mas descritivo e, portanto, de análise

${ }^{6}$ Com excepcionalidades notáveis, como Josette Féral, André Helbo, Marco De Marinis, José Maria Paz Gago, para mencionar alguns casos conhecidos.

${ }^{7}$ Ver Ladislav Mateika e Erwin R. Titunik Mateika, 1976. do espetáculo. Estudamos, sem dúvida, a teatralidade pós-moderna, talvez 


\section{Urdimento}

${ }^{8}$ Ver meu estudo sobre este problema em 0 teatro de Samuel Beckett e o fim da modernidade, 2010 a.
${ }^{9}$ Neologismo do autor, não-doxa, não-opinião. (NT) não com a exaustividade de outras práticas artísticas, mas os estudos estão aí, mesmo se os queiram ignorar, correndo o risco de aventurar-se por um caminho de originalidade a todo preço que, no fim das contas, não leva a nada.

Depois da "morte" do texto e do autor, que fazer? Como continuar? A resposta vai vir do teatro pós-moderno. Este teatro, assim como a condição pós-moderna, não é uniforme e por essa razão toda tentativa de sistematização a partir de estruturas profundas ou de convergências estão condenadas ao fracasso. A grande diversidade do teatro pós-moderno é equivalente à pluralidade cultural e aqui está a dificuldade de sistematização. O importante é tentar capturar e compreender as estratégias textuais e políticas, como a dimensão estética e ética, não para sistematizá-las, mas para melhor penetrar no tipo de teatralidade e de performance vinculadas a uma performatividade particular e capturar o projeto teatral.

Depois de 1950, particularmente depois da escritura performativa de Samuel Beckett, o teatro tal qual havíamos conhecido se imobiliza: ${ }^{8}$ tudo que se segue é a performance de uma palavra sempre diferida. A escritura beckettiana coincide com o fim da modernidade, posto que conduz ao fim da modernidade.

O que vem depois de Beckett e dos anos de 1950 é a teatralidade e a performance teatral pós-moderna, desde 1960 até o final do século vinte. De meu ponto de vista estão intimamente vinculadas com a simulação, tal qual a definiu Jean Baudrillard. Mas também está vinculada com a apropriação discursiva segundo a noção de Barthes ("a morte do autor"), a de Foucault ("Que é um autor?") e a de Bakhtin ("a heteroglossia”). Essa apropriação eu chamo de intertextualidade e codificação dupla (JENCKS, 1989, p. 10 e 14). Some-se a isso um regresso à ficção, a narrativização que, de outro lado, é similar à que sucede na pintura e na arquitetura pós-modernas.

Na performance teatral pós-moderna existem três funções centrais:

a) a função estética, que aponta a desmistificação do ato criativo e coloca a criação como retextualização e apropriação de textualidades, onde a gloriosa originalidade modernista é obliterada;

b) uma função crítica/reflexiva de textualidades precedentes, onde o intertexto estabelece uma relação com o novo texto que fala do presente. É aqui onde se encontra a dupla codificação que permite reconhecer a origem da apropriação e sua função em relação à recepção.

A intertextualidade possui uma relação direta com a dupla codificação, como se pode observar na pintura de Carlo Maria Mariani La Mano Ubbidisce a'll Intelecto (1983), e Clio Observing the Fifth Style (1985), de Stephen Mackenna, 
en The Idleness of Sisyphus (1981), de Sandro Chia ou, ainda, em The Disquieting Muses (After de Chirico) (1982), de Andy Warhol.

c) uma função política centrada na des-doxificação ${ }^{9}$ de representações artísticas que levam a politizá-las em um ato de distanciamento.

A seguir, gostaria de dar exemplos de performance teatral pós-modernas presentes na maioria de textos teatrais deste período.

Primeiro exemplo: Rosencrantz e Guildestern estão mortos (1967), de Tom Stoppard, introduz a performance pós-moderna. Há aqui dois intertex tos: Esperando Godot e Hamlet.

O primeiro se manifesta no diálogo entre Guildestern e Rosencrantz: a cada vez que as duas personagens se encontram sós, ou seja, em seu próprio espaço discursivo, o diálogo é uma réplica de Vladimir e Estragon. Esses diálogos são jogos de palavras sem nenhum sentido específico, mas procuram acalmar a consciência do tempo e seus destinos indeterminados. O segundo intertexto apresenta segmentos de Shakespeare com o inglês da época, introduzidos literalmente no hipertex to de Stoppard, que indica a cena e o ato de onde os retirou.

A pergunta que se impõe é: porque eleger estas duas personagens, normalmente eliminadas das encenações? Poderíamos afirmar que Stoppard deseja que não se veja o mundo através de Hamlet, mas através de Guil e Ros. O problema por trás desta eleição se funda, a meu ver, num profundo questionamento do abuso de poder por parte de Hamlet e da coroa, de um lado, o rei exige que Guil e Ros acompanhem Hamlet a Inglaterra. Eles ignoram, no texto de Shakespeare, que a carta que levam ao rei da Inglaterra condena Hamlet à morte. Este fato, em si, constitui um abuso, uma vez que eles não têm ideia de sua missão. De outro lado, como sabemos, Hamlet descobre a carta e a reescreve, condenando à morte os mensageiros, uma morte injusta, gratuita $\mathrm{e}$ absurda: Guil e Ros não são culpados de nada, exceto terem aceitado a ordem do rei. Uma ordem que eles não podem não aceitar e que os vai perseguir durante toda a obra.

Guil: There was a messenger... that's right. We were sent for. (17)

Guil: Then a messenger arrived we have been sent for. (18)

Ros: It was urgent a matter of extreme urgency, a royal summons, his very words: official business and no questions asked. (19) 


\section{Urdimento}

São, portanto, vítimas de um duplo abuso de poder: da parte do rei e da parte de Hamlet. No texto de Stoppard, sem dúvida, há uma diferença fundamental: Guil e Ros abrem a carta e se informam sobre seu conteúdo. Porque essa mudança? Simplesmente para demonstrar a impotência desses miseráveis que não têm outro caminho senão obedecer. Mas Hamlet, conhecendo o conteúdo, possui uma escolha : não condená-los à morte. Essa leitura de Stoppard muda radicalmente nossa percepção de Hamlet, desviando nossa atenção da vingança do príncipe da Dinamarca e concentrando-nos no duplo abuso do poder : o destino de Guil e Ros foi imediatamente decidido no instante mesmo em que obedeceram a ordem do rei:

Guil: "A weaker man might be moved to re-examine his faith, if in nothing else at least in the law of probability" (12).

Guil: "It must be indicative of something else, besides the redistribution of wealth" (16).

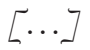

Guil: "We have not been... picked out... simply to be abandoned... set loose to find our own way... We are entitled to some direction.... I would have thought" (20).

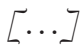

Ros: "I want to go home".

Guil: "Don't let them confuse you" (37).

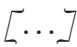

Ros: "I'm out of my step here-" (38).

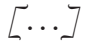

Ros: "Over my step over my head body! - I tell you it's all stopping to a death, it's boding to a depth, stepping to a head, it's all heading to a dead stop-" (38).

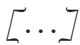


Guil: "Pragmatism?! -is that all you have to offer? You seem to have no conception of where we stand! Tou won't find the answer written down for you in the bowl of a compass. - I can tell you. Besides you can never tell this far north-it's probably dark out there" (58-59).

$$
[\cdots]
$$

Guil: "Wheels have been set in motion, and they have their own pace, to which we are... condemned. Each move is dictated by the previous one- that is meaning of order. If we start being arbitrary it'll just be a shambles" (60).

\section{$[\cdots]$}

Ros: "They'll have us hanging about till we're dead" (93).

$$
[\cdots]
$$

Guil: "I like to know where I am. Even if I don't know where I am, I like to know that. If we go there's no knowing".

Ros: "No knowing what?".

Guil: If we'll ever come back" (95).<smiles>[CH]1C=C[CH-]1</smiles>

Ros: "But we've got nothing to go on, we're out on our own" (104).<smiles>[CH]1C=C[CH-]1</smiles>

Guil: "We've traveled too far, and our momentum has taken over; we move idly towards eternity, without possibility of reprieve or hope of explanation" (121).

$$
[\cdots]
$$

Guil: Our names shouted in a certain dawn ... a message... a summons... There must have been a moment, at the beginning where we could have said -no. But how we missed it" (125). 
Assim, Stoppard escreve nos interstícios de Shakespeare, no não dito do texto, nos fazendo refletir sobre o abuso de poder nos anos 1960 no Ocidente.

Segundo exemplo: Antígona furiosa (1989), de Griselda Gambaro, se inscreve nas fissuras do texto de Sófocles e revela o não dito em Antígona, porém seu texto retém a estrutura do original: o enterro de Polinice. Gambaro introduz duas sequências sobre a miséria em Buenos Aires e a devastação contínua, combinada com segmentos metaficcionais como a superposição do presente (um café) e do passado (fragmentos do intertexto), a luta de Policine e Etéocles.

O texto de Gambaro põe em questão o poder do Estado: as personagens Antínoo e Corifeu assumem personagens do intertexto e Antígona não é executada por Creonte (ausente no texto e apresentado somente através de narração por uma personificação indireta de Corifeu e Antínoo). Ela se suicida, porém, num ato de libertação, desqualificando assim a autoridade do Estado e de Creonte:

Antígona: Não terminará nunca a zombaria? Irmão, não posso suportar estas paredes que não vejo, este ar que oprime como uma pedra. A sede (Apanha a tigela, a levanta e a leva à boca. Fica imóvel). Beberei e vou continuar sedenta, meus lábios vão quebrar e minha língua espessa se transformará em um animal mudo. Não. Rejeito este conto de misericórdia, que lhes serve de dissimulação à crueldade. (lentamente, vira-se). Com a boca umida da minha própria saliva irei para a minha morte. Orgulhosamente, Hêmon, irei para a minha morte. E virás correndo e se cravarás a espada. Eu não o sei. Nasci para repartir o amor e não o ódio. (pausa longa). Porém o ódio manda. (furiosa) O resto é silêncio! (morre, com fúria) (1989, p. 217)

Antígona propõe um olhar diferente, onde é ela quem controla seu próprio destino. Uma posição muito distinta à de sua irmã Ismênia, que no original diz "eu cedi à força, eu não tenho nada a ganhar me rebelando". Se Creonte a havia perdoado, ela elege o suicídio para desafiar um mundo que vive em função da barbárie, do ódio e da morte. Suas palavras são lapidares: "Nasci para repartir o amor e não o ódio. Porém o ódio manda".

Antígona desafia o patriarcado ao oferecer sua vida com a intenção de mudar a ordem estabelecida. Gambaro não nos apresenta a visão de Creonte, mas sim a de uma mulher que sacode o olhar do mundo com um olhar feminino. Ela propõe um mundo que deve ser governado pelo amor e não pelo ódio: há aqui não somente a mensagem, mas também a relação reflexiva entre o passado e o presente. 
A escritura palimpséstica de Gambaro se inscreve em uma reflexão que nos obriga a olhar para trás com a intenção tomarmos consciência de que esse estado de coisas não mudou desde as tragédias gregas. O mundo é ainda o mesmo e isso é inaceitável para Antígona/Gambaro. Finalmente, ela nos obriga a questionar-nos: por que as coisas devem ser assim?

\section{Conclusão}

Parece-me surpreendente esta constante constatação da teoria teatral atual. A pós-modernidade acabou, e para aqueles que trabalhamos sobre a globalização da cultura não podemos estar senão profundamente surpreendidos pela decisão do teatro que se faz atualmente em relação a outros campos transdisciplinares. Surpreendentes são também as afirmações universalistas e radicais, tais como "a vanguarda está morta”, "o teatro pós-dramático é um novo paradigma”, etc. É difícil aceitar tais afirmações quando o corpus estudado deixa completamente de lado, por exemplo, o teatro latinoamericano, canadense, etc. Tudo acontece como se o resto do mundo não existisse. Talvez, devido à minha origem latinoamericana e canadense, eu esperasse um pouco de modéstia da parte de culturas que se consideram ainda dominantes, porque existem práticas artísticas e teatrais bastante ricas, bastando pensar no México, Brasil, Argentina ou Canadá, para não falar de práticas teatrais sobre as quais não posso pronunciar-me devido à minha profunda ignorância.

\section{Referências bibliográficas}

AUBIGNAC, François-Hédelin, Abbé d'. La pratique du théâtre. Nachdruck der dreibandigen Ausgabe Amsterdam 1715 mit einer einleitenden Abhandlung von Hans-Jorg Neuschafer. Genève: Slatkine Reprints, 1971 (1715).

AUSTIN, John L. How to Do Things with Words. Second Edition. J. O. Urmson et Marina Sbisà, Editeurs. Cambridge, Massachusetts: Harvard University Press, 1975 .

BAKHTIN, Mikhail. The Dialogic Imagination. Austin, Texas: Austin University Press, 1981.

BARTHES, Roland. Le théâtre de Baudelaire In: Essais critiques. Paris: Éditions du Seuil, 1964 (1954), pp. 41-47.

Outubro 2010 - № 150 que é performance? Entre a teatralidade e a performatividade... Fernando de Toro 
Littérature et signification In: Essais critiques. Paris: Éditions du Seuil, 1964 (1963), pp. 258-276.

La mort de l'auteur In: Le bruissement de la langue. Essais critiques IV). Paris: Éditions du Seuil, 1984 (1971), pp. 63-69. (Publicado originalmente en 1971 en Manteia).

BAUDRILLARD, Jean. Simulacres et Simulation. Paris: Éditions Galilée, 1981.

BERTENS, Hans. The Postmodern Weltanschaung and its Relation to Modernism: An Introductory Survey In: A Postmodern Reader. Edited by Joseph Natoli and Linda Hutcheon. New York: State University of New York Press, 1986, pp. 25-70.

Routledge, 1995.

The Idea of the Postmodern: A History. London and New York:

BIRRINGER, Johannes. Theatre, Theory, Postmodernism. Bloomington, Indiana, p. Indiana University Press, 1991.

DE TORO, Alfonso. Entre el teatro kinésico y el teatro deconstruccionista de Eduardo Pavlovsky In: La Escena Latinoamericana, n. 7 (diciembre), p. 1-3, 1990.

Hacia un modelo para el teatro postmoderno In: Semiótica y teatro latinoamericano. Fernando de Toro, Editor. Buenos Aires: Editorial Galerna, 1990, pp. 13-42.

Semiósis teatral postmoderna, intento de un modelo Gestos, Año 5, 9 (Abril), p. 23-52, 1990.

Cambio de paradigma, el 'nuevo' teatro latinoamericano o la constitución de la postmodernidad espectacular. Iberoamericana, 1/2, 43/44: 70-92, 1991.

Postmodernidad en cuatro dramaturgos latinoamericanos In: De la Colonia a la Postmodernidad. ROSTER, Peter; ROJAS, Mario (Ed.). Buenos Aires/Ottawa: Editorial Galerna/IITCTL, 1992, pp. 157-176.

El teatro postmoderno de Eduardo Pavlovsky In: Variaciones del teatro latinoamericano: Tendencias y perspectivas. DE TORO, Alfonso; PÔRTL, Klaus (Ed.). Frankfurt am Main: Vervuert Verlag, 1996, pp. 59-84.

DE TORO, Fernando. El teatro de Samuel Beckett y el fin de la Modernidad In: Intersecciones III: Ensayos sobre literatura, teatro, arquitectura, pintura, música y cultura. Buenos Aires: Editorial Galerna, 2010a. 
Aires: Editorial Galerna, 2010b.

¿Qué fue la postmodernidad? Más allá del Post. Buenos

DI GAETANI, John L. A Search for a Postmodern theatre. Interviews with Contemporary Playwrights. New York: Greenwood Press, 1991.

DUCROT, Oswald. Présupposés et sous-entendus. Langue française, 4 (février), 1969, p. 30-43.

111 , Les indéfinis et 1'énonciation. Langages, n. 17, 1970, p. 91-

FÉRAL, Josette. Performance and Theatricality: The Subject Demytified. Modern Drama. XXV, 1 (March), 1982, p. 170-181,

FOUCAULT, Michel. Qu'est-ce que un auteur? In: Dites et Écrits I, 1954-1975. Paris: Éditions Gallimard, 1994 (1969), pp. 817-849.

GAMBARO, Griselda. Antígona furiosa In: Teatro 3. Buenos Aires: Ediciones de la Flor, pp. 195-217. (Inclue: "Viaje de invierno"; "Sólo un aspecto"; "La gracia"; "El miedo"; "Decir sí”; "Antígona furiosa” y otras piezas breves), 1989.

GOFFMAN, Ervin. The Presentation of Self in Everyday Life. New York: Doubleday, 1959.

Frame Analysis: An Essay on the Organisation of Experience. New York, Evanston, San Francisco and London: Harper and Row Publishers, 1974 .

GOLDBERG, RoseLee. Performance Art. From Futurism to the Present. London/ New York: Thames and Hudson World of Art, 2001 (1979).

GROTOWSKI, Jerzy. Vers un thêatre pauvre. Lausanne: Éditions L’Age d'Homme, 1971.

HABERMAS, Jûrgen. Modernity - An Incomplete Project In: The Anti-Aesthetic. Essays on Postmodern Culture. Edited and with an Introduction by Hal Foster. Nes York: The New York Press, 1998 (1983), pp. 1-15.

HELBO, André. Le théâtre: texte ou spectacle vivant? Paris: Klincksieck, 2007.

JENCKS, Charles. What is Post-Modernism? Third Edition. New York: St. Martin's Press, 1989.

KAPROW, Allan. Essays on the Blurring of Art and Life. Berkeley, Los Angeles/ London: University of California Press, 1993.

Outubro 2010 - № 150 que é performance? Entre a teatralidade e a performatividade... Fernando de Toro 


\section{Urdimento}

Participation Performance In: Essays on the Blurring of Art and Life. Berkeley/Los Angeles/ London: University of California Press, 1993a, pp. 181-194.

Performing Life In: Essays on the Blurring of Art and Life. Berkeley/Los Angeles/London: University of California Press, 1993b, pp. 195198.

KIRBY, Michael. Editor. Happenings. An illustrated Anthology. Scripts and productions by Jim Dine, Red Grooms, Allan Kaprow, Claies Oldenburg and Robert Whitman. New York: Dutton, 1965.

Dutton, 1969. The Art of Time. Essays on the Avant-Gard. New York: E. P.

Editor. The New Theatre. Performance Documentation. The Drama Review Series. New York: New York University Press, 1974.

LYOTARD, Jean-Francois. La condition postmoderne. Paris: Les Editions de Minuit, 1979.

LEHMANN, Hans-Thies. Le théâtre postdramatique. Paris: L’Arche, 2002.

MATEJKA, Ladislav; TITUNIK, Erwin R. (Ed.). Semiotics of Art. Prague School Contributions. Cambridge/Massachusetts/London, England: The MIT Press, 1976.

PORTOGHESI, Paolo. Postmodernism. New York: Rizzoli, 1983.

RECANATI, François. La transparence et l'énonciation. Pour introduire à la pragmatique. Paris Éditions du Seuil, 1979.

32, 1980, p. 190-215, Qu'est-ce qu'un acte locutionnaire? Communications, $n$.

SCHECHNER, Richard. Performance Theory. Revised and expanded edition, with a new preface by the author. London/New York: Routledge, 2009 (1977).

SEARLE, John R. Expression and Meaning. Studies in the Theory of Speech Acts. Cambridge/England: Cambridge University Press, 1969.

STOPPARD, Tom. Rosencrantz and Guildenstern are dead. New York: Grove Weidenfeld, 1967.

WILLIAMS, Raymond Lesli. The Postmodern Novel in Latin America. Politics, Culture, and the Crisis of Truth. London: Macmillan, 1995. 


\section{NORMAS PARA PUBLICAÇÃO DE ARTIGOS}

A Revista Urdimento é uma publicação do Programa de Pós-Graduação em Teatro da Universidade do Estado de Santa Catarina e reúne artigos que contribuiem para a pesquisa na área das artes cênicas.

A Urdimento recebe as colaborações em fluxo contínuo que são analisadas pelo Conselho Editorial. As seguintes normas técnicas devem ser observadas para a publicação das contribuições.

1) Os artigos devem ter no mínimo 8 e máximo 12 laudas. Resenhas de livros entre 3 e 4 laudas. Os textos deverão ser digitados com letra Times New Roman, tamanho 12, com espaçamento $1,5 \mathrm{~cm}$ em Word para Windows (ou compatível).

2) Os colaboradores devem incluir dados especificando as atividades que exercem, a instituição (se for o caso) em que trabalham e dados básicos dos respectivos currículos.

3) Solicita-se clareza e objetividade nos títulos.

4) Os artigos devem vir acompanhados de resumo com no máximo de 6 linhas e 3 palavras-chaves, ambos com as respectivas traduções para o inglês.

5) O envio do artigo original implica na autorização para publicação, tanto na forma imprensa como digital da revista.

6) Notas explicativas serão aceitas desde que sejam imprescindíveis e breves. As citações no corpo do texto que sejam superiores a 5 linhas devem ser digitadas em espaço simples com tamanho 10 em itálico. As citações no corpo do texto devem seguir a formatação (AUTOR, 2008, p.1).

7) Todas as palavras em língua estrangeira devem estar em itálico.

8) As notas de rodapé devem ser apresentadas no fim de cada página e numeradas em algarismos arábicos.

9) Caso os artigos incluam fotos, desenhos ou materiais gráficos da autoria de terceiros, é indispensável carta de autorização. $\mathrm{O}$ 
material deverá vir acompanho de legendas de identificação. $\mathrm{O}$ material gráfico deve ser reduzido ao mínimo indispensável, em formato JPG e com resolução de 300 dpi, enviadas em arquivos separados do texto. Somente serão publicadas imagens em preto e branco.

10) O material para a publicação deverá ser encaminhado em duas vias impressas e uma em formato digital (programa word) para o e-mail urdimento@udesc.br aos cuidados da revista.

Endereço para correspondência e envio de colaborações:

\section{Revista Urdimento}

Programa de Pós-Graduação em Teatro - UDESC

Av. Madre Benvenuta, 1.907 - Itacorubi 88.035-001 - Florianópolis - SC

E-mail: urdimento@udesc.br

\section{Normas para citação de referência bibliográfica:}

\section{Livros}

SOBRENOME, Prenomes do autor. Título: subtítulo. edição. Local: editor, ano de publicação.

\section{Teses/ Dissertações/Monografias}

SOBRENOME, Prenomes do autor. Título: subtítulo. ano. $\mathrm{n}^{\mathrm{o}}$ total de páginas.Tese, Dissertação ou Monografia (grau e área) - Unidade de Ensino, Instituição, Local e ano.

\section{Artigos de periódicos na internet}

SOBRENOME, Prenomes do autor. Título do artigo. Título da Revista, local, volume, número, páginas do artigo, mês e ano de publicação. Notas. Disponível em: <http://www....> Acesso em: dia mês (abreviado) ano, hora: minutos.

\section{Artigos}

SOBRENOME, Prenomes do autor do artigo. Título do artigo. Título da Revista, local, volume, número, páginas do artigo (inicial e final), mês e ano da publicação do artigo. 
Realização:

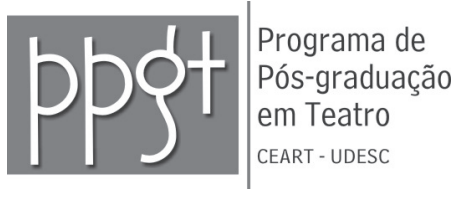

Programa de Pós-Graduação em Teatro

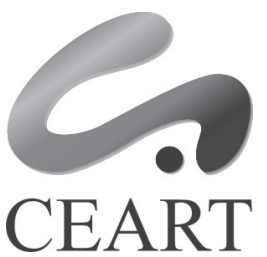

Centro de Artes 